\title{
Analysis of Internet Insurance Financial Return Rate and Its Influencing Factors
}

\author{
Guanshang Shao \\ School of Business Administration, South China University of Technology, Guangzhou, China \\ Email: scut_shaogs@163.com
}

How to cite this paper: Shao, G.S. (2019) Analysis of Internet Insurance Financial Return Rate and Its Influencing Factors. Modern Economy, 10, 537-546. https://doi.org/10.4236/me.2019.102037

Received: January 16, 2019

Accepted: February 23, 2019

Published: February 26, 2019

Copyright ( 2019 by author(s) and Scientific Research Publishing Inc. This work is licensed under the Creative Commons Attribution International License (CC BY 4.0).

http://creativecommons.org/licenses/by/4.0/

\begin{abstract}
This paper takes Internet insurance wealth management products as the research object, and selects the products of China Life Jiatian Tiantianying as the representative, and studies the influencing factors of the yield of such products through relevant time series empirical methods. The results show that the interbank lending rate, bond market, exchange rate, securities secondary market and insurance institution strength have different degrees of impact on the rate of return. The research in this paper will help to improve the theoretical methods of Internet wealth management products, especially in the insurance sector. At the same time, it can better help investors rationally choose the right products for investment and supervision to prevent market risks.
\end{abstract}

\section{Keywords}

Internet Insurance Financing, Rate of Return, Influencing Factors

\section{Introduction}

According to statistics from the China Internet Information Center, as of the end of June 2018, the number of Internet users in China reached 802 million, and the Internet penetration rate was $57.7 \%$. The public's reliance on the Internet continued to increase. At the same time, with the steady increase of per capita disposable income of Chinese residents, it reached 26,000 yuan by the end of 2017, up 9\% year-on-year; while the proportion of savings deposits to individual investable assets decreased year by year. This shows that while residents are accumulating wealth, their financial management concepts are gradually opening up. It is also gradually opening up, and the demand for financial management such as securities, funds and insurance is constantly increasing. Since June 2013, the balance of treasures triggered the Internet financial crisis, the domestic ma- 
jor e-commerce and traditional financial institutions including banks, brokerages, insurance, etc. have successively issued similar wealth management products through Internet channels, and various Internet financial tools have flourished. However, with the advancement of the currency marketization process, the loss of the advantages of the money fund, the yield of the network wealth management products that rely on the money fund are declining, and the current annual rate of return of the balance has dropped to around 3\%. Internet wealth management products are not only the scope of money funds, but in order to seek higher returns, insurance wealth management products gradually enter the field of investors. With the gradual liberalization of insurance investment targets and the better risk control capabilities of insurance, this product with both insurance and wealth management properties has become a public investment after bank financing and "baby" cash management tools.

Internet insurance is an insurance product that is issued, underwritten or managed by an insurance company and is regulated by the Banking Insurance Regulatory Commission. Its investment scope is larger than that of the money fund, and the expected income is stable and ready for withdrawal. It is a medium-risk product based on investment in higher liquid assets, and its risk is higher than that of the monetary fund and regular wealth management. At present, domestic and foreign scholars have already conducted in-depth research on the profitability of Internet wealth management products. However, due to the relatively late development of Internet insurance asset management products, there are few related studies.

\section{Literature Review}

Regarding the status quo of Internet insurance financing development, foreign research mainly focuses on third-party electronic payment and online P2P mode, and most of them focus on the analysis of the promotion status of emerging Internet financial management models and the influencing factors of investor behavior of financial platform. Domestic research is mostly based on the research of Yu'ebao. Wu Xiaoqiu [1] conducted an in-depth study on the survival logic of the Internet wealth management industry from the definition, shape, operation mode and risk characteristics of Internet finance. It was found that the development of Internet finance and traditional finance complement each other. The Internet finance industry can improve the original. Some financial structures improve the efficiency of financial functions. Chen Jian [2] believes that in the innovation of China's Internet financial platform, the influence of third-party payment on the public is more prominent, and Yu'ebao will profoundly change the payment methods and savings concepts of the public. Qiu Junping et al. [3] took Yu'ebao as an example and found that the perceived ease of use and perceived usefulness of products are the main determinants of the behavioral intentions of participating entities. In addition, Internet insurance products are also in their category. Li Kemu [4] pointed out that Internet insurance is at the forefront in the innovation and development of Internet finance, 
and due to the lack of historical data, Internet insurance may have product pricing risks. Wang Yan et al. [5] analyzed the advantages and disadvantages of Internet insurance financing in the personal wealth management market, and put forward corresponding suggestions for future supervision.

Regarding the research status of the characteristics of the rate of return and the influencing factors, the domestic and foreign characteristics of the investment income fluctuations of various types of financial products have been more deeply understood. The ARCH model proposed by Engle [6] has achieved great success and is widely used in the study of stocks and bonds and financial time series such as interest rates and exchange rates. Later, on the basis of this, the researchers extended the ARCH model such as GARCH model and EGARCH model to explain the error variance, which can better describe the income characteristics of financial wealth management products. In the domestic research on the yield of wealth management products, Wang Weiqing et al. [7] explained the impact of the actual income of commercial banks' wealth management products from the perspective of macro factors, mainly related to the one-year time deposit interest rate; based on the SVARGARCH-M model, Deng Xusheng et al. [8] found that the expected yield of China's collective trust products is affected by the bond repo rate and price level; Zhu Hongmei [9] uses the regression method to obtain short-term credit products pricing reference deposit benchmark interest rate and market interest rate; Li Yazhen [10] adopted. The monetary policy transmission mechanism for analyzing the profitability of wealth management products, using empirical tools to find out that the M2 growth rate has an impact on the profitability of wealth management products. In response to the characteristics of Internet wealth management products, Bai Jie and Lin Lian [11] used the EMD method to find that the marginal rate of return is a long-term trend of interest rates determined by the domestic market funds, low-frequency vibrations caused by major events in the financial industry, and normal market fluctuations. The high frequency vibration is composed of three aspects. Yang Yi and Liu Liu [12] and Lu Jinglian [13] both use the empirical method of linear regression to test. The results show that the Shanghai Interbank Offered Rate has a significant positive impact on the marginal rate of return, while the Yubao yield to Shanghai the impact of interbank offered rates is not significant. Zhuang Lei [14] pointed out through the Granger causality test that the bond yield does not constitute a causal relationship with the Internet financial yield. With the random effects of panel data and FGLS regression methods, Lin Wensheng et al. [15] found that Shibor, stock market, bond market, wealth management product fund scale, and seasonal changes all have significant effects on the profitability of wealth management products.

Based on the existing research, this paper aims to analyze the impact rate of the factors affecting the rate of return by analyzing the rate of return on the Internet insurance wealth management products represented by China Life Jianian Tiantianying, so as to better help investors. Rationally choose the right product for investment. 


\section{Analysis of the Characteristics of Wealth Management Products}

For Internet insurance wealth management products, before 2015, the insurance wealth management market was dominated by medium and short-term universal insurance and investment-linked insurance. However, due to regulatory requirements, universal insurance and investment-linked insurance almost disappeared from Internet financial channels. Now it is replaced by individuals. It is now replaced by an individual pension management product. The endowment insurance management product refers to the personal endowment insurance management product issued by the endowment insurance company approved by the China Insurance Regulatory Commission. The endowment insurance company accepts the entrustment of individual customers to provide endowment insurance and funds management services related to endowment insurance. Only professional pension insurance companies have the qualifications for the sale of pension insurance products, including Xinhua Pension, Pingan Pension, Taiping Pension, China Life Pension, Yangtze River Pension, Taikang Pension, Anbang Pension, and Chinese People's Pension Insurance Company.

The previous insurance and financial management has both insurance and financial management functions, but the current Internet insurance wealth management products basically eliminate the insurance function, leaving only the financial management function. Dividend insurance and universal insurance belong to life insurance. After the death of the holder, the beneficiary defaults to the legal heir, but in fact other financial products also have this function. In general, Internet insurance wealth management products strive to achieve higher yields on the basis of meeting the needs of security and liquidity through selection of projects with moderate deadlines, low risks and high returns. With the characteristics of "stable capital, wide investment scope, high liquidity and low threshold", it is more suitable for stable investors and young people who are used to purchasing financial resources in the Internet.

\subsection{Represented by "Guo Shou Jia Nian Tian Tian Ying"}

In the wealth management platform with more than 100 million users and a total transaction volume of over 2 trillion, insurance and wealth management products such as "Guo Shou Jia Nian Tian Tian Ying" have been in the best-selling list of the platform and are loved by investors. This article selects the insurance wealth management products on behalf of the China Life Jiatian Tiantianying products on the Licaitong platform, on the one hand because the product is in the first place in the insurance management platform of the Licaitong platform, and on the other hand, the manager Caitong platform disclosed that as of 2018. At the end of September, the total turnover of Guoshou Jianian Tiantianying products has reached 59.66 million, and the cumulative number of transactions is far from the similar products of the platform. Therefore, it has a relatively high representativeness. 


\subsection{Medium-Risk Wealth Management Products Investing in High Liquidity Tools}

Internet insurance wealth management products mainly invest in bank deposits with good liquidity, short-term bonds and other financial products with higher credit ratings. They do not participate in stock assets in any form, and are not affected by fluctuations in the stock market. They strictly control the credit risk of securitized financial products. On the platform of the wealth management, insurance wealth management products are medium risk. Taking Guoshou Jianian Tiantianying products as an example, it follows the principle of prudent and diversified risks, and fully considers the safety, profitability and liquidity of the pension security management portfolio property, thus implementing professional management.

\section{Theoretical Mechanism and Data Description}

Referring to the existing research, after comprehensive thinking, we will select the influencing factors such as Shibor, stock market, bond market, and money supply into the model. Below we will separately explain the theoretical mechanism and data, and put forward test hypotheses.

1) Interbank lending rate

In China's banking market, the level of deposit interest rates usually shows the degree of financial tension in the market. The Shanghai Interbank Offered Rate (Shibor) reflects the cost of interbank lending funds in the financial market and can well reflect the demand for funds in the market, usually as a reference standard for determining market interest rates.

2) Bond market conditions

The research selected in this paper is the product of China Life Jianian Tiantianying Investment fixed income assets including bank time deposits, bank agreement deposits, bond funds, fixed income insurance asset management products, financial enterprise (company) bonds, non-financial enterprise (company) bonds. The ratio of government bonds and quasi-government bonds with a remaining maturity of more than one year is $0 \%-190 \%$, which is quite high. Therefore, the market of bond market will also affect the income of Internet insurance wealth management products. This paper selects the one-year government bond yield to represent the market situation of the bond market.

3) Exchange rate

As China gradually moves to the world, the uncertainty of the international environment has brought great impact to China's financial market. In particular, the Sino-US trade war that has been launched since 2018 is a "black swan event", giving domestic and foreign funds. The circulation has a great impact, so the impact of the RMB exchange rate on the capital side of China's money market will be greater and greater. The exchange rate changes affect the financial flows of domestic and foreign financial markets, which affects financial products, and Internet insurance and wealth management products also belong to them. This 
paper selects the central parity of the US dollar against the RMB as the exchange rate data to study the impact of exchange rate changes on the yield of Internet insurance wealth management products.

4) Securities secondary market

The securities market reflects the preference of the financial investment market for risk capital. The downturn in the securities market will attract a large amount of capital into the non-securities market. Internet insurance is one of the options. This paper selects the Shanghai Stock Index to study the impact of the development of the securities secondary market on the rate of return.

5) Insurance institution strength

The investment manager's investment ability will have a certain degree of impact on the profitability of wealth management products. The administrators of Internet insurance wealth management products are mainly insurance institutions, so it is also important to judge the strength of insurance institutions. This paper examines its impact on profitability by selecting the Wind Insurance II Index to represent the strengths of the insurance industry and institutions.

Based on the above theoretical mechanism, it can be seen that the following hypothesis is proposed:

- Hypothesis 1: Interbank lending rates have a negative impact on the yield of Internet insurance wealth management products.

- Hypothesis 2: The bond market has a positive impact on the yield of Internet insurance wealth management products.

- Hypothesis 3: The exchange rate has a reverse impact on the yield of Internet insurance wealth management products.

- Hypothesis 4: The secondary market of securities has a negative impact on the yield of Internet insurance products.

- Hypothesis 5: The strength of insurance institutions has a positive impact on the profitability of Internet insurance products.

\section{Empirical Test}

This paper selects China Life's Jiatian Tiantianying from Tencent Wealth Management Insurance Products as a representative to study the profitability of Internet insurance wealth management products. At the same time, this paper selects the 10,000-yuan income of China Life Jiatian Tiantianying to represent the yield of this product. Through the tracking of the data of the wealth management platform during the research period, a total of 400 data were selected from July 31, 2017 to September 03, 2018. The distribution of the yield of Guoshou Jianian Tiantianying is shown in Figure 1.

Taking into account the availability and consistency of the data, the profit rate (GS) of China Life Jiatian Tiantianying from July 31, 2017 to September 3, 2018 is taken as the explanatory variable, and then the corresponding Shanghai Bank is selected. Interbank interest rate (Shibor) overnight interest rate on a daily basis, one-year government bond yield (GZ) on a daily basis, exchange rate (LV) on a daily basis, Shanghai Stock Exchange Index (SZ) on a daily basis, Wind 


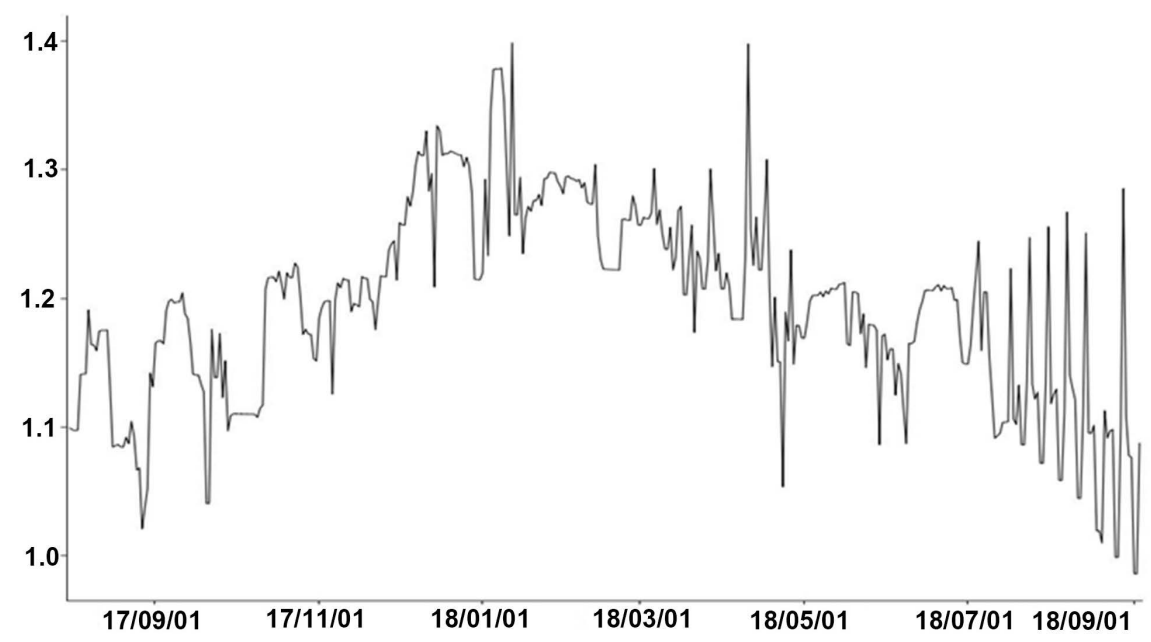

Figure 1. Distribution of the yield of Guoshou Jianian Tiantianying.

Insurance. The II Index (BX) is in Japanese. The above data are from the Wind economic database.

Considering the factors such as weekends and holidays, some of the missing data may not be matched. Therefore, based on the daily calculation period, the rest day data is calculated by the average interpolation method.

For time series data, it is necessary to conduct a stationarity test before analysis to avoid the occurrence of pseudo-regression. This paper uses the unit root test $(\mathrm{ADF})$ to determine whether there is a unit root in the sequence, and there is no unit root. That is, the sequence is judged to be a stable sequence, and the relevant results are shown in Table 1.

And Table 2 shows the description statistics for the variables.

The multivariate linear regression model was established by stepwise regression method to obtain the following model 1.

$$
G S=\alpha+\beta_{1} \cdot \text { Shibor }+\beta_{2} \cdot G Z+\beta_{3} \cdot L V+\beta_{4} \cdot S Z+\beta_{5} \cdot B X
$$

The final regression results are shown in Table 3.

From the regression results, it can be obtained that the value of $\mathrm{R}^{2}$ is slightly larger and the model fit is better. And the value of each coefficient is significant. Among the five explanatory variables, the coefficients of GZ and BX are positive, the coefficients of Shibor, LV and SZ are negative, and both are significantly 0 at the level of $1 \%$, and the assumption that the coefficient is 0 at the level of $99 \%$. The above results show that the Shanghai Interbank Offered Rate (Shibor) has a negative impact on the yield of Internet insurance wealth management products. The one-year Treasury yield (GZ) maintains a significant rate of return on Internet insurance wealth management products. Positive factors, exchange rate (LV) have a negative impact on the yield of Internet insurance wealth management products. The Shanghai Stock Exchange Index (SZ) has a significant negative impact on the rate of return on Internet insurance products, Insurance II Wind Index (BX) there is a positive correlation between the yields of Internet insurance products. Therefore, we can judge the changes in the yield curve of 
Table 1. Stability analysis result.

\begin{tabular}{cccc}
\hline & Variable letter representation & Prob. $^{*}$ & Conclusion \\
\hline The yield & GS & 0.0000 & Stable \\
Interbank lending rate & Shibor & 0.0000 & Stable \\
Bond market conditions & $\mathrm{GZ}$ & 0.0000 & Stable \\
Exchange Rate & $\mathrm{LV}$ & 0.0010 & Stable \\
Securities secondary market & $\mathrm{SZ}$ & 0.0000 & Stable \\
Insurance institution strength & $\mathrm{BX}$ & 0.0000 & Stable \\
\hline
\end{tabular}

Table 2. The description statistic of the variable.

\begin{tabular}{ccccc}
\hline & Mean & Standard deviation & Skewness & Kurtosis \\
\hline GS & 1.19 & 0.08 & -0.11 & 0.12 \\
Shibor & 2.61 & 0.21 & -2.11 & 0.12 \\
GZ & 3.33 & 0.25 & -0.31 & 0.12 \\
BX & 6.53 & 0.17 & 0.18 & 0.12 \\
LV & 3190.40 & 221.94 & -0.83 & 0.12 \\
SZ & 1847.45 & 183.14 & 0.45 & 0.12 \\
\hline
\end{tabular}

Table 3. Data stability analysis result.

\begin{tabular}{|c|c|c|c|}
\hline & Coefficient & Standard deviation & Prob. ${ }^{*}$ \\
\hline$\alpha$ & $1.507^{\star * *}$ & 2.927 & 0.004 \\
\hline Shibor & $-0.240^{\star \star \star}$ & 0.029 & 0.000 \\
\hline GZ & $0.542^{* * *}$ & 0.053 & 0.000 \\
\hline LV & $-1.106^{\star * *}$ & 0.087 & 0.000 \\
\hline $\mathrm{SZ}$ & $-0.143^{\star \star \star}$ & 0.052 & 0.006 \\
\hline $\mathrm{BX}$ & $0.196^{\star * *}$ & 0.026 & 0.000 \\
\hline \multicolumn{4}{|c|}{$\mathrm{R}^{2}=0.676$} \\
\hline
\end{tabular}

Note: ${ }^{* *},{ }^{* *}$, and ${ }^{*}$ indicate significant levels of significance at $1 \%, 5 \%$, and $10 \%$, respectively.

Internet insurance wealth management products through observation changes, so as to provide investors with a certain guiding role.

\section{Conclusions}

This paper firstly explains the possible factors affecting the profit rate of Internet insurance wealth management products from the perspective of theoretical mechanism. Finally, through the establishment of multiple linear regression model, the relevant predictions are tested and the following conclusions are obtained.

The research results show that the Shanghai Interbank Offered Rate (Shibor) has a negative impact on the yield of Internet insurance wealth management products. The one-year Treasury yield (GZ) maintains a significant rate of return on Internet insurance wealth management products. The one-year Treasury 
yield (GZ) has a significant positive impact on the yield of Internet insurance wealth management products. Exchange rate (LV) has a negative impact on the yield of Internet insurance wealth management products. The Shanghai Stock Exchange Index (SZ) has a significant negative impact on the rate of return on Internet insurance products. The Insurance II Wind Index (BX) has a positive correlation with the rate of return on Internet insurance wealth management products.

\section{Policy Recommendations}

1) For regulators, the regulatory mechanism for Internet insurance products is not perfect. Especially after the introduction of new regulations, the management of new and old products in the market is still in the stage of exploration. The regulators should be based on the income of various products. Characteristics and developments develop appropriate policies to guide the market to issue appropriate and compliant financial products, maintain prudent principles, and control sales channels so that insurance assets can participate in benign competition.

2) For financial institutions, especially insurance institutions, because of the late development of insurance asset management products, in the current regulatory environment of "going to just exchange and expecting revenue-oriented products", the asset allocation experience accumulated by insurance funds has been accumulated for a long time. Combine the investment ability of public funds, and cultivate and motivate relevant investment talents, continuously enrich and improve the investment strategy of Internet insurance and wealth management, and build a competitive insurance asset management company.

3) For investors, when the current overall market is sluggish and other investment and financial management tools are sluggish, the robust Internet insurance wealth management products provide investors with a new investment option. At the same time, the risk of Internet insurance wealth management products is higher than that of money funds and regular wealth management, and investors cannot ignore their potential risks.

\section{Conflicts of Interest}

The author declares no conflicts of interest regarding the publication of this paper.

\section{References}

[1] Wu, X.Q. 2015) Internet Finance: The Logic of Growth. Finance and Trade Economics, 36, 5-15.

[2] Chen, J. (2014) On Internet Finance Innovation-Based on the Perspective of Third-Party Payment Alipay. China Market, No. 2, 63-65.

[3] Qiu, J.P., Yang, Q. and Guo, L.L. (2015) Research on the Factors Affecting the Use of Internet Financial Management Products. Journal of Information, No. 1, 179-184.

[4] Li, K.M. (2014) Network Insurance and Risk Prevention. China Finance, No. 8, 
13-14.

[5] Wang, Y., Yang, X.M. and Xu, X.T. (2015) Research on the Status Quo and Prospects of Internet Insurance in China. Economic Research Guide, No. 5, 207-210.

[6] Engle, R.F. (1982) A general Approach to Lagrange Multiplier Model Diagnostics. Journal of Econometrics, 20, 83-104. https://doi.org/10.1016/0304-4076(82)90104-X

[7] Wang, W.Q. and Cui, L. (2011) Development Status and Related Suggestions of Personal Financial Management Business of China's Commercial Banks. Finance and Accounting Monthly, No. 4, 36-38.

[8] Deng, X.S. and Xiao, J.W. (2012) Influencing Factors and Market Risk Assessment of Expected Rate of Return of Collective Trust Products in China-An Empirical Study Based on SVAR-GARCH-M Model and Factor Analysis Method. Journal of Zhongnan University of Economics and Law, No. 2, 113-118.

[9] Zhu, H.M. (2012) Empirical Research on the Pricing of Bank Wealth Management Products-From the Perspective of Interest Rate Marketization. Investment Research, No. 9, 151-156.

[10] Li, Y.Z. (2014) Empirical Study on the Impact of Financial Products Yield on Money Supply. Statistics and Decision, No. 17, 153-156.

[11] Bai, J. and Lin, L.L. (2014) Research on the Forecast of Yu'e Bao's Yield Based on EMD-GARCH. Management Modernization, 34, 117-119.

[12] Yang, Y. and Liu, L. (2014) The Relationship between Yu'e Bao's Rate of Return and Shanghai Interbank Offered Rate. Finance and Accounting Monthly, No. 20, 70-72.

[13] Lu, J.L., Xue, Z.Z. and Zhou, Q. (2015) An Empirical Study of the Impact of Interbank Offered Rate on Yu'e Bao Yield. Credit, 33, 71-74.

[14] Zhuang, L. (2015) An Empirical Study on the Fluctuation of the Yield of the National Debt and the National Debt Market. Economics and Management, 29, 74-79.

[15] Lin, W.S. and Zhang, Z.Y. (2016) Factors Affecting the Rate of Return of Internet Financial Wealth Management Products. Financial Forum, No. 11, 52-60. 